\title{
NARRATIVA NO FLUXO DE INFORMAÇÃO DURANTE O COMPARTILHAMENTO DE CONHECIMENTO EM MICRO E PEQUENAS EMPRESAS: UM ESTUDO MULTICASO
}

\section{NARRATIVE IN THE INFORMATION FLOW DURING THE KNOWLEDGE SHARING IN MICRO AND SMALL COMPANIES: A MULTI-CASE STUDY}

\author{
Tatiana Cristina Siqueira Santos ${ }^{a}$ \\ Dorzeli Salete Trzeciak ${ }^{b}$ \\ Gregório Varvakisc
}

\begin{abstract}
RESUMO
Introdução: Ao mesmo tempo em que a criação de novos conhecimentos é promovida pela estrutura das micro e pequenas empresas, acredita-se que, boa parte dessas empresas não tem um processo sistematizado que permite compartilhar todo esse conhecimento, gerando valor para o negócio. Objetivo: Observar a narrativa no fluxo de informação durante o compartilhamento de conhecimento e de que modo ela sustenta a melhoria dos processos e práticas de serviços, em micro e pequenas empresas. Metodologia: É uma pesquisa aplicada, com abordagem qualitativa e, ainda, exploratória e descritiva. Utiliza o estudo multicaso como procedimento técnico para a sua realização, tendo como universo de pesquisa, empresas participantes dos Núcleos Setoriais da Associação Comercial e Industrial de Florianópolis. Resultados: As evidências da pesquisa apontam que as narrativas sustentam o desenvolvimento de melhores práticas de serviço, incrementando os resultados e a competitividades das empresas, a partir da ação racionalizada e dirigida pela gestão. Tais práticas têm como canal o fluxo de informações do próprio processo, dependem dos conhecimentos dos gestores-proprietários e apresentam-se em nível individual. Conclusões: $O$ estudo deixa como contribuição uma nova perspectiva em relação à análise do fluxo de informação com a inserção da narrativa para sustentar a melhorias dos processos e das práticas organizacionais em micro e pequenas empresas.
\end{abstract}

\footnotetext{
a Mestre em Ciência da Informação pela Universidade Federal de Santa Catarina (UFSC). Email: taticss@yahoo.com.br

b Doutora em Engenharia de Produção pela Universidade Federal de Santa Catarina (UFSC). E-mail: dorzeli@gmail.com

c Doutor em Manufacturing Engineering pela Loughborough University, Inglaterra. E-mail: g.varvakis@ufsc.br
}

Inf. Inf., Londrina, v. 23, n. 2, p. 395 - 426, maio/ago. 2018.

http://www.uel.br/revistas/informacao / 
Descritores: Fluxo de informação. Compartilhamento de conhecimento. Micro e pequenas empresas. Narrativa.

\section{INTRODUÇÃO}

As micro e pequenas empresas (MPEs), de acordo com Durst e Edvardsson (2012) tendem a ser menos formais, ou seja, pouco burocráticas, com estrutura plana, estilo de gestão orgânico e livres de flutuação que estimula o empreendedorismo e a inovação. Gassmann e Keupp (2007) apontam uma tendência dessas empresas em investir mais em ativos tangíveis do que em áreas relacionadas diretamente à vantagem competitiva do negócio - principalmente as de serviços - e à capacidade de seus funcionários melhorarem as práticas e inovarem, com base em conhecimento. Em geral, se observa que as MPEs são consideradas como criadoras de conhecimento, porém carentes no que se refere a sua retenção (ALE EBRAHIM; AHMED; TAHA, 2010). Isso permite pensar que, ao mesmo tempo em que a criação de novos conhecimentos é facilitada pela estrutura das MPEs, boa parte delas não possui um processo sistematizado para aproveitar todo esse conhecimento e gerar valor para o negócio.

Pode-se considerar que o conhecimento nas MPEs está centrado nas pessoas, e devido às peculiaridades dessas empresas, os indivíduos detém o conhecimento de forma única, e esses conhecimentos são complementares e frequentemente não se sobrepõem. Dificilmente duas pessoas executarão uma mesma atividade de modo igual, mesmo que em algumas situações, os resultados da prática possam ser semelhantes. Nesse sentido, as narrativas são formas de criar e de compartilhar o conhecimento no ambiente organizacional, liderando os indivíduos para a ação (BOISOT; LI, 2006; BRUSAMOLIN, 2006; DENNING, 2006; GARGIULO, 2006), portanto, dentro da perspectiva deste estudo, oferecer condições de melhorar as práticas de serviços. 
Assim, para serem bem sucedidas, as MPEs precisam melhorar seus produtos (bens e serviços) e processos, explorando a narrativa para aprimorar os fluxos durante o compartilhamento de conhecimentos (SANTOS, 2014).

Neste cenário, o artigo busca investigar como acontece a narrativa no fluxo de informação para compartilhar conhecimento e de que maneira ela sustenta a melhoria de processos e práticas de serviços em MPEs. Para tanto, descreve a prática de 9 (nove) micro e pequenas empresas, membros da Associação Comercial e Industrial de Florianópolis (ACIF).

Para atingir seu propósito o artigo estrutura-se em: introdução, em que se apresenta o contexto, a problemática e o objetivo do estudo; procedimentos metodológicos, com a descrição das etapas adotadas para a realização da pesquisa; fundamentação teórica, que aborda a temática em estudo; resultados da observação da narrativa no fluxo de informação durante o compartilhamento de conhecimento em MPEs e; considerações finais do estudo.

\section{PROCEDIMENTOS METODOLÓGICOS}

Esta pesquisa, do ponto de vista da sua natureza, enquadra-se como aplicada, sendo a sua principal característica contribuir para fins práticos, ou seja, aplicar ou utilizar, mais ou menos imediatamente, os resultados na solução de problemas que ocorrem na realidade (MARCONI; LAKATOS, 2007).

No que se refere à abordagem do problema, trata-se de pesquisa qualitativa, compreendida como um processo não matemático de interpretação, que visa descobrir conceitos e relações nos dados brutos e organizá-los em um esquema explanatório teórico (STRAUSS; CORBIN, 2008).

Quanto aos seus objetivos, a pesquisa é exploratória e descritiva. Estudos exploratórios visam proporcionar maior familiaridade com determinado problema, para deixá-lo mais claro (YIN, 2005), e os descritivos objetivam descrever as características de determinada população ou fenômeno, ou estabelecer relações entre variáveis (GIL, 1999).

Como procedimento técnico, utilizou-se o estudo de caso, pesquisa empírica que investiga um fenômeno contemporâneo dentro do seu real 
contexto. Trata-se de uma estratégia adequada para responder questões do tipo "como" e "por que", favorável ao pesquisador que possui pouco ou nenhum controle em relação aos acontecimentos num determinado contexto (YIN, 2005). Foi realizado um estudo multicaso, que de acordo com Triviños (1987), refere-se a um estudo de caso aplicado em mais de uma população.

O universo de pesquisa foi o das empresas participantes dos Núcleos Setoriais da Associação Comercial e Industrial de Florianópolis (ACIF). A ACIF busca o desenvolvimento e fortalecimento das MPEs, por meio do associativismo, e contribui com o desenvolvimento socioeconômico de Florianópolis, auxiliando na geração de empregos, ocupação e renda e, principalmente, por estimular que os empreendedores unam forças, compartilhem conhecimentos e criem soluções inovadoras para problemas comuns. De acordo com Durst e Edvardsson (2012), as pequenas empresas tendem a colocar mais ênfase na troca de experiências e conhecimentos do que as empresas maiores, porém os canais de comunicação nessas pequenas empresas são mais propensos a se realizar entre empresas do que no âmbito interno da organização. Por esse motivo, a discussão neste estudo não fica em nível de Núcleos. Buscou-se investigar como acontece o compartilhamento de conhecimento, internamente, nas empresas. Portanto, a seleção da amostra foi realizada de acordo com os critérios pré-definidos: ser um Núcleo em atividade (com reuniões recorrentes) e ser composto por empresas prestadoras de serviços. Primeiramente, definiram-se os três (3) Núcleos participantes e, na sequência, as empresas interessadas em contribuir com a pesquisa.

Os Núcleos participantes apresentam objetivos que vão desde aumentar o resultado financeiro das empresas nucleadas por meio de qualificação, troca de experiências e fortalecimento do associativismo, até o desenvolvimento de propostas para levar aos clientes soluções para a gestão de seus negócios; incrementar a rede de relacionamentos; fomentar o empreendedorismo e; buscar representatividade.

Os sujeitos da pesquisa foram os gestores-proprietários de nove (9) empresas selecionadas. De acordo com Boisot (2006) os gestores constituem 
uma unificação dominante na organização, pois codificam e abstraem escolhas, compartilham práticas, objetivos, papeis e rotinas e, por meio disso, criam uma lógica dominante. Assim, se constituem como essenciais ao desenvolvimento das MPEs.

Os dados coletados para a pesquisa são do tipo primário, adquiridos em entrevistas presenciais, e permitiram obter informações sobre a narrativa no compartilhamento de conhecimento e como o gestor conhece, sente, realiza ou pretende realizá-la, e também as suas explicações sobre os acontecimentos. $O$ roteiro de entrevistas foi estruturado de acordo com o modelo teórico (apresentado no item 3.3), contemplando perguntas abertas e fechadas sobre cada elemento no contexto das fases do processo de compartilhamento de conhecimento (iniciação, implementação, apoio e incorporação).

O conteúdo dos dados coletados foi analisado com base na metodologia de Bardin (2009), organizada em: i) pré-análise; ii) exploração do material e; iii) tratamento dos resultados, inferência e interpretação. A pesquisa foi realizada no período de dezembro de 2013 a fevereiro de 2014.

\section{FUNDAMENTAÇÃO TEÓRICA}

Nesta seção apresenta-se, de modo sucinto, a fundamentação teórica que subsidiou a estruturação do modelo de análise e discussão dos resultados sobre a narrativa no fluxo de informação durante o compartilhamento de conhecimento. Trata, inicialmente de aspectos relacionados aos fluxos de informação, seus elementos e processos, a partir da apresentação e explicação dos modelos utilizados como referência. $\mathrm{Na}$ sequência, aborda a narrativa como aspecto relevante no fluxo de informação uma vez que, por meio dela, ocorre a transmissão de conhecimento a partir da articulação de várias informações, dados, contexto. Para finalizar apresenta o modelo da narrativa no fluxo de informação, base de observação e análise dos dados. 


\subsection{Fluxos de Informação e seus elementos}

Barreto (1999) e Valentim (2010) compreendem fluxo de informação como um canal estruturado, que sustenta as melhores práticas, a partir da transmissão de informações estimuladoras dos processos cognitivos que criam conhecimentos novos. Nesse cenário, segundo Barreto (1999, p. 70) informações são "estruturas simbolicamente significantes com a competência de gerar conhecimento no indivíduo, em seu grupo, ou na sociedade."

Há vários modelos que ilustram os fluxos de informação, conforme aponta pesquisa na área de Ciência da Informação (CURTY, 2005; INOMATA, 2012; PASSOS, 2012). Para este estudo, buscou-se conhecer os fluxos no contexto organizacional, internos à organização e criados e disseminados pelos gestores-proprietários a sua equipe de trabalhadores. Os modelos de fluxos apresentados a seguir fornecem um panorama geral da forma como os canais são estruturados para disseminar informação e conhecimentos nas organizações.

No Modelo de Lesca e Almeida (1994) tem-se uma visão de trabalho dos fluxos sob o ponto de vista dos micro e pequenos estabelecimentos, em que os gestores-proprietários são os principais responsáveis pela busca de fontes externas e a tradução dessas informações e conhecimentos em conhecimentos úteis para a organização, objetivando criar os fluxos internos.

O Modelo de Choo (2006) apresenta uma estruturação para os fluxos internos da organização como ferramenta administrativa para auxiliar no aproveitamento da experiência e conhecimento da equipe, por meio da criação de significados comuns, exploração de novos conhecimentos e comprometimento com certas direções de ação.

No Modelo de Tonet e Paz (2006) o compartilhamento de conhecimento é caracterizado como um processo integrado, composto por um conjunto de quatro fases que disseminam informações, ideias, sugestões e experiências relevantes à organização. A fase de iniciação compreende ações responsáveis por identificar e analisar as necessidades de conhecimentos e as 
oportunidades existentes para empregá-las; na etapa de implementação são observadas as ações que alavancam a integração entre fontes (emissores) e destinatários (receptores) do conhecimento; na fase de apoio, desenvolvem-se oportunidades de aperfeiçoamento do conhecimento compartilhado e promovem-se orientações de prática, até ocorrer a assimilação do conhecimento e o desenvolvimento das habilidades necessárias ao uso proficiente e; na última etapa, de incorporação do conhecimento compartilhado, desenvolvem-se ações para sustentar o fluxo entre aqueles que irão utilizá-lo.

Os Modelos de Barreto (2001) e Boisot e Li (2006) fornecem uma visão da narrativa centrada no gestor-proprietários e na articulação dos seus conhecimentos. Nos modelos de Choo (2006), Boisot (1995 apud CHOO, 2006) e Tonet e Paz (2006) a etapa de incorporação e uso é apresentada genericamente, e o seu monitoramento pela gerência demonstrará o impacto da adoção do novo conhecimento pela organização. Por fim, o Modelo de Boisot (1998) dá ênfase ao conhecimento tácito incorporado, bem como a sua trajetória de construção em nível organizacional e na capacidade inovativa das organizações.

No tocante aos elementos que caracterizam o fluxo de informação, buscou-se compreendê-los como as principais variáveis de análise e, com isso, levantar subsídios para auxiliar na construção do modelo que descreve a narrativa no fluxo de informação para o compartilhamento de conhecimento em MPEs, conforme apresentado no item 3.3, deste artigo.

Os elementos do fluxo de informação são: atores (emissores e receptores) (BARRETO, 1994); canais e fontes (VALENTIM, 2010); tecnologias da informação e comunicação (CHOO, 2006); barreiras (GONÇALVES; RAMOS; SANTOS, 2009). Para gerar valor à organização, entende-se que precisa existir uma conexão entre o emissor e o receptor, de modo e levá-lo a refletir sobre o conhecimento novo e enxergá-lo como importante, tanto para o seu trabalho como para si próprio (TONET; PAZ, 2006). Portanto, é importante o modo como o receptor percebe uma fonte em um contexto no qual a informação é recebida. Os canais de comunicação impactam na qualidade dos 
processos de absorção e incorporação de novo conhecimento e como defende Choo (2006), esses canais utilizados pelas pessoas face a face são ricos, uma vez que permitem lidar com incertezas e indefinições, focar nos reais problemas, solucionar diferenças e estimular a criatividade. Para 0 armazenamento e recuperação e, ainda, para trocas e interações entre emissores e receptores, as tecnologias da informação e comunicação também se apresentam como excelentes opções de canais.

\subsection{Narrativa}

Com a finalidade de descobrir meios para expressar o indizível, utilizando a linguagem figurativa e simbólica para articular suas intuições e insights e disseminar seu conhecimento incorporado (tácito), muitos gerentes recorrem a narrativa (NONAKA, 2000).

De acordo com Brusamolin (2011), narrativas de histórias ou simplesmente narrativas, são relatos orais ou escritos, de um ou mais eventos, que podem ser verdadeiros ou fictícios. A diferença entre uma história e a citação de um exemplo, como aponta o autor, está na adição de conteúdo emocional e detalhes sensoriais na narrativa.

Gargiulo (2006) trata a construção narrativa como histórias e aponta as seguintes funções que podem facilitar a comunicação e a disseminação de conhecimento: dá poder ao narrador, ajudando-o a criar um ambiente, codifica informações e é uma ferramenta para pensar.

Quando bem empregadas, as narrativas são instrumentos que auxiliam no aumento do poder de liderança do emissor, por meio da elaboração de mensagens construídas a partir da articulação entre conhecimentos codificados, incorporados, e estruturados de acordo com o grau de codificação e abstração, com a utilização de metáforas, analogias, fatos, exemplos, histórias para buscar atingir propósitos claros e bem definidos (GARGIULO, 2006; NONAKA, 2000; SOLE; WILSON, 2002; DENNING, 2006).

Histórias podem ser úteis nos contextos em que se deseja lançar uma nova ideia, integrar novos membros, mediar relacionamentos e compartilhar 
sabedoria e melhores práticas, como apontam Sole e Wilson (2002). Para esses autores, a técnica de articular histórias na narrativa (storytelling) pode ser utilizada para o compartilhamento de conhecimentos tácitos simples.

Nota-se, assim, a narrativa presente em dois momentos no fluxo de informação: na criação de conhecimento, sob a perspectiva cognitiva relacionada relativa à estrutura do pensamento e da mensagem, e na disseminação, conforme a estrutura do fluxo de informação da organização, levando em conta que esses aspectos (criação e disseminação) se retroalimentam.

\subsection{Modelo para Observação e Análise da Narrativa no Fluxo de Informação para o Compartilhamento de Conhecimento}

O modelo para observação e análise da narrativa no fluxo de informação para o compartilhamento de conhecimento objetiva auxiliar na compreensão e descrição de como ocorre a narrativa no ambiente das MPEs, além contribuir para a melhoria de práticas no ambiente organizacional (SANTOS, 2014).

Para a elaboração do modelo, foram considerados subsídios apresentados pelos autores Lesca e Almeida (1994), Barreto (2002), Boisot e Li (2006), Sole e Wilson (2002), Brusamolin (2006), Denning (2006), Valentim (2010), Curty (2005), Inomata (2012), Tonet e Paz (2006) e Passos (2012), relacionados principalmente a fluxo de informação, narrativas e compartilhamento de conhecimento.

A Figura 1 ilustra o modelo desenvolvido por Santos (2014), que parte da essência da composição de um fluxo de informação: emissor, receptor e mensagem (narrativa). A leitura que se pode fazer do modelo é o destaque centralizado na pessoa que emite o conhecimento, o emissor (gestorproprietário, nas MPEs) e, ao redor dele, sob seus domínios, os elementos: monitoramento do ambiente, fontes, formas de interação, mecanismos de suporte e mensagem. Os elementos são acionados ao passo que o gestor avança nas etapas do processo de compartilhamento de conhecimento iniciação, implementação, apoio e incorporação (TONET; PAZ, 2006). O 
detalhamento das etapas foi apresentado no item 3.1 deste artigo.

Figura 1 - Modelo da narrativa no fluxo de informação

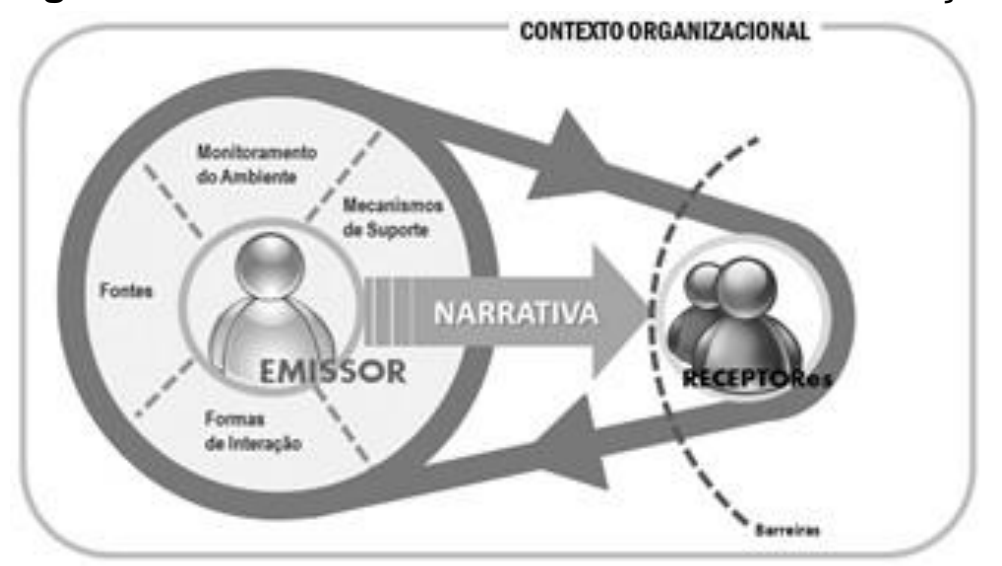

Fonte: Santos (2014, p. 84).

Destaca-se que o emissor sustenta o fluxo realizando o monitoramento do ambiente e identificando as oportunidades que o levam a interagir com alguém, o receptor. Entretanto, para que se tenha a geração dos resultados desejados com essa interação, o emissor seleciona de modo adequado as fontes e os mecanismos que suportam a mensagem central a ser transmitida e, da mesma forma, a interação que se demonstre mais adequada, ou seja, argumentos, metáforas, exemplos, manuais, documentos impressos. A mensagem narrativa é construída pelo emissor para conectar as informações e conhecimentos, suportados ou não por elementos físicos (dependendo do grau de codificação), e confere a eles um sentido. Utilizar estrategicamente esses elementos tem como finalidade vencer as barreiras da comunicação e do compartilhamento de conhecimento e alcançar os objetivos de disseminação de novos conhecimentos, desenvolvimento de competências e mudança de comportamentos (SANTOS, 2014). Na sequência apresenta-se o detalhamento do modelo apresentado na Figura 1.

Emissor: produtor de informação e possuidor de conhecimento para interagir com receptores e estabelecer significados comuns, desenvolver competências e mudar comportamentos para alcançar os objetivos organizacionais (CHOO, 2006). 
Receptor(es): indivíduos que apresentam a expectativa ou a necessidade de adquirir determinado conhecimento. Os principais receptores de interação são: profissionais (equipe); clientes; fornecedores; gerentes e sócios e; outros gestores e empresários (BRUSAMOLIN; MORESI, 2008).

Narrativa (mensagem): mensagem a ser compartilhada e, segundo Tonet e Paz (2006), o conteúdo presente nessa mensagem precisa ter validade e utilidade. As mensagens que fazem parte do fluxo de informação produzido e consumido pela empresa podem ser caracterizadas como informações de convívio (possibilitam aos indivíduos conviver e interagir) e informações de atividade (informação necessária para iniciar, realizar e controlar as operações relacionadas ao funcionamento da empresa, podendo ser em nível operacional e/ou estratégico) (LESCA; ALMEIDA, 1994).

Monitoramento do ambiente: atividade constante da gestão, para acompanhar a situação atual e identificar oportunidades para interagir e compartilhar conhecimento conforme propósitos estabelecidos, para, com base no gap identificado, buscar a melhor estratégia de interação, além de identificar práticas que podem ser empregadas para estabelecer um contexto propício para criar e compartilhar conhecimento (BRUSAMOLIN, 2006; CLARKE; MONKHOUSE, 1995 apud TONET; PAZ, 2006; DENNING, 2006; SOLE; WILSON, 2002).

Fontes: fatores geradores de argumentações e explicações para explanar a mensagem compartilhada e chegar próximo da compreensão e ação (TONET; PAZ, 2006). Exemplos de fontes: experiências vividas; livros, revistas ou jornais; televisão; novela, filmes, telejornais; histórias na própria empresa; sites na Internet, e-mail; conteúdo de treinamentos e cursos; ou criação, no sentido de criar uma história, exemplo, metáfora ou situação para facilitar o entendimento e fixar na memória (BRUSAMOLIN; MORESI, 2008).

Formas de interação: os canais e as condições de como acontecem os fluxos de informação na narrativa entre os indivíduos na organização, tais como telefone, e-mail e redes sociais; sistema de gerenciamento da empresa (software) e/ou repositórios internos de documentos (virtuais e/ou físicos); 
conversas individuais e em grupo; conversas durante o expediente; forma sincrônica e diacrônica e; local exclusivo ou sala exclusiva (BRUSAMOLIN, 2006).

Mecanismos de suporte: são outras estratégias ou modos de compartilhar conhecimento e que podem sustentar a narrativa: narrativa de histórias (storytelling); modelagem; simulações; recursos codificados e; objetos simbólicos (SOLE; WILSON, 2002).

Barreiras: podem estar relacionadas a qualquer estágio do processo de compartilhamento de conhecimento, desde 0 planejamento até 0 acompanhamento e controle dos resultados, como por exemplo: falta de tempo para pensar em um discurso/história ou para conversar e interagir; resistência do receptor em adquirir o conhecimento; treinamento insuficiente dos usuários para a aplicação do conhecimento (TONET; PAZ, 2006; DENNING, 2006; BRUSAMOLIM, 2006).

Inseridos no contexto de compartilhamento de conhecimento e analisados sob essa perspectiva, os elementos do modelo apresentam-se relevantes por indicar os parâmetros de análise de forma concisa, permitindo uma sistematização da narrativa como um método capaz de sustentar o processo de melhoria das MPEs.

\section{OBSERVAÇÃo E ANÁLISE DA NARRATIVA NO FLUXO DE INFORMAÇÃO DURANTE O COMPARTILHAMENTO DE CONHECIMENTO EM PMES}

Nesta seção apresentam-se os resultados obtidos com os participantes da pesquisa, de acordo com os elementos do modelo da narrativa no fluxo de informação, interpretado em cada uma das quatro fases do compartilhamento de conhecimento de Tonet e Paz (2006): iniciação, implementação, apoio e incorporação. Procurou-se evidenciar os aspectos positivos de cada caso, sem comparações, iniciando-se com a apresentação dos elementos essenciais do fluxo de informação e o contexto empresarial no qual a pesquisa foi aplicada. 


\subsection{Elementos Essenciais do Fluxo de Informação}

Os componentes de um fluxo de informação são essencialmente: os atores (emissor e receptor), o contexto e o conhecimento, neste caso na forma narrativa. Cada elemento é caracterizado de modo geral para as empresas pesquisadas, possibilitando evidenciar mais adiante, aspectos impactantes nas construções narrativas das MPEs. Neste sentido, no Quadro 1, apresenta-se resumidamente o a caracterização das empresas pesquisadas.

Quadro 1 - Características das MPEs pesquisadas

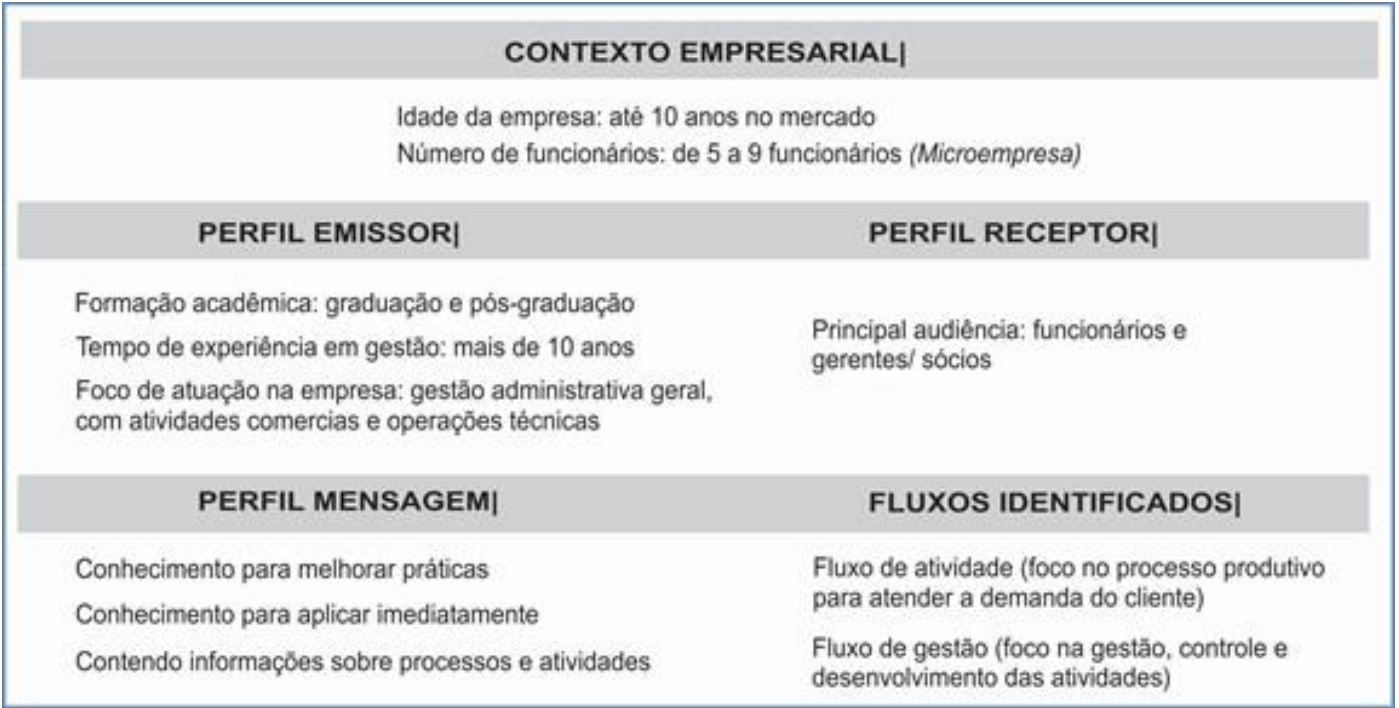

Fonte: Dados da pesquisa (2014).

O ambiente empresarial da pesquisa caracteriza-se pela predominância de microempresa (com até 10 funcionários), que possuem até 10 anos de existência no mercado e contam com um perfil de gestores graduados e pósgraduados, com mais de 10 anos de experiência em gestão de negócios. Percebeu-se que as interações narrativas dos gestores acontecem com 0 principal foco de receptores: funcionários/gerentes/sócios, configurando, de modo geral, que as informações produzidas e narradas pelos gestoresproprietários são destinadas prioritariamente para uso interno da empresa, conforme classificação de Lesca e Almeida (1994).

Foi possível identificar dois fluxos de informação centrais nas MPEs pesquisadas. Um deles se caracteriza pela produção da atividade fim da 
empresa e é iniciado pela demanda do cliente e finalizado na entrega do serviço, contemplando todo o processo de produção (operação técnica); o outro fluxo de informação está relacionado à gestão (controle e desenvolvimento) dos serviços e processos. Ambos acontecem ou não com a interação direta dos proprietários, dependendo do nível de estruturação do negócio.

Em relação às mensagens narrativas emitidas pelas MPEs pesquisadas, no que se refere ao uso, são em sua maioria constituídas de informações para aplicação imediata, com direcionamento mais acentuado à melhoria de práticas, do que destinadas à resolução de problemas. Quanto à característica das mensagens, no que se refere ao conteúdo, conforme classificação de Lesca e Almeida (1994), a narrativa das empresas pesquisadas equilibra conteúdos detentores de certo grau de formalidade sobre processos de trabalho e estratégias, com conteúdo mais informal e utilitário, que aborda o significado das atividades, facilitando o convívio das pessoas com o trabalho na empresa. Ou seja, baseados em Lesca e Almeida (1994) o nível de compartilhamento de conhecimento não se define simplesmente com a troca de informações sobre processos de rotina e como fazer as atividades, mas 0 que fazer e por que fazer configuram a presença do nível estratégico e de significado nas narrativas, impactando na direção e no comportamento dos profissionais dentro da organização. Esses dois tipos de informação são, de acordo com os autores, imprescindíveis tanto para a existência do negócio como para a sua evolução, e se fazem presentes na composição das mensagens narrativas das empresas pesquisadas.

Compreende-se então, que mesmo se tratando de estruturas e negócios diferenciados, a maioria das MPEs pesquisadas tem gestores que participam ativamente do fluxo de informação que produz o serviço, elaborando narrativas cercadas de conteúdo para a melhoria das práticas de trabalho, com aplicação imediata. Com base em Tonet e Paz (2006), ao enfatizarem que a aplicabilidade do conhecimento está diretamente relacionada ao valor que ele oferece, tanto para a organização quanto para os funcionários na execução de 
suas atividades, constatou-se, em geral, clareza e foco na comunicação dos gestores em relação a sua contribuição para o compartilhamento de conhecimentos que agregam valor ao negócio.

Nas próximas seções são apresentados os resultados referentes às estratégias mais utilizadas, durante o processo de compartilhamento de conhecimento, pelas MPEs em suas construções narrativas.

\subsection{Fase de Iniciação da Narrativa no Compartilhamento de Conhecimento nas MPEs}

A narrativa no fluxo de informação tem início a partir do monitoramento do ambiente, com o acompanhamento das necessidades e oportunidades de empregar novos conhecimentos, que servem de estímulos para que o emissor estabeleça um propósito de interação, de acordo com suas fontes de conhecimentos. No entanto, os fluxos de informações são sustentados na organização desde que sejam estabelecidos ambientes favoráveis às interações.

A relevância dessa etapa para o processo de compartilhamento relaciona-se a dificuldade de se localizarem as demandas existentes; em perceber oportunidades de transferir para outros conhecimentos úteis e já dominados, ou não; e em manter um contexto favorável para as buscas e criação de conhecimentos (TONET; PAZ, 2006). Dessa forma, foi analisada a fase inicial do compartilhamento de conhecimento, apresentando os resultados do fluxo de informação das MPEs de acordo com os elementos: monitoramento do ambiente (motivação e propósitos); fontes de informações, argumentos e histórias e; as práticas para manter um ambiente favorável ao compartilhamento. Esses aspectos estão sumarizados no Quadro 2, apontando os resultados obtidos junto as empresas pesquisadas. Salienta-se que os números que aparecem nos elementos ordenam as respostas por frequência de repetição, ou seja, o número (1) repetiu mais vezes que o (2) e assim sucessivamente. 
Quadro 2 - Elementos do fluxo que iniciam a narrativa em MPEs

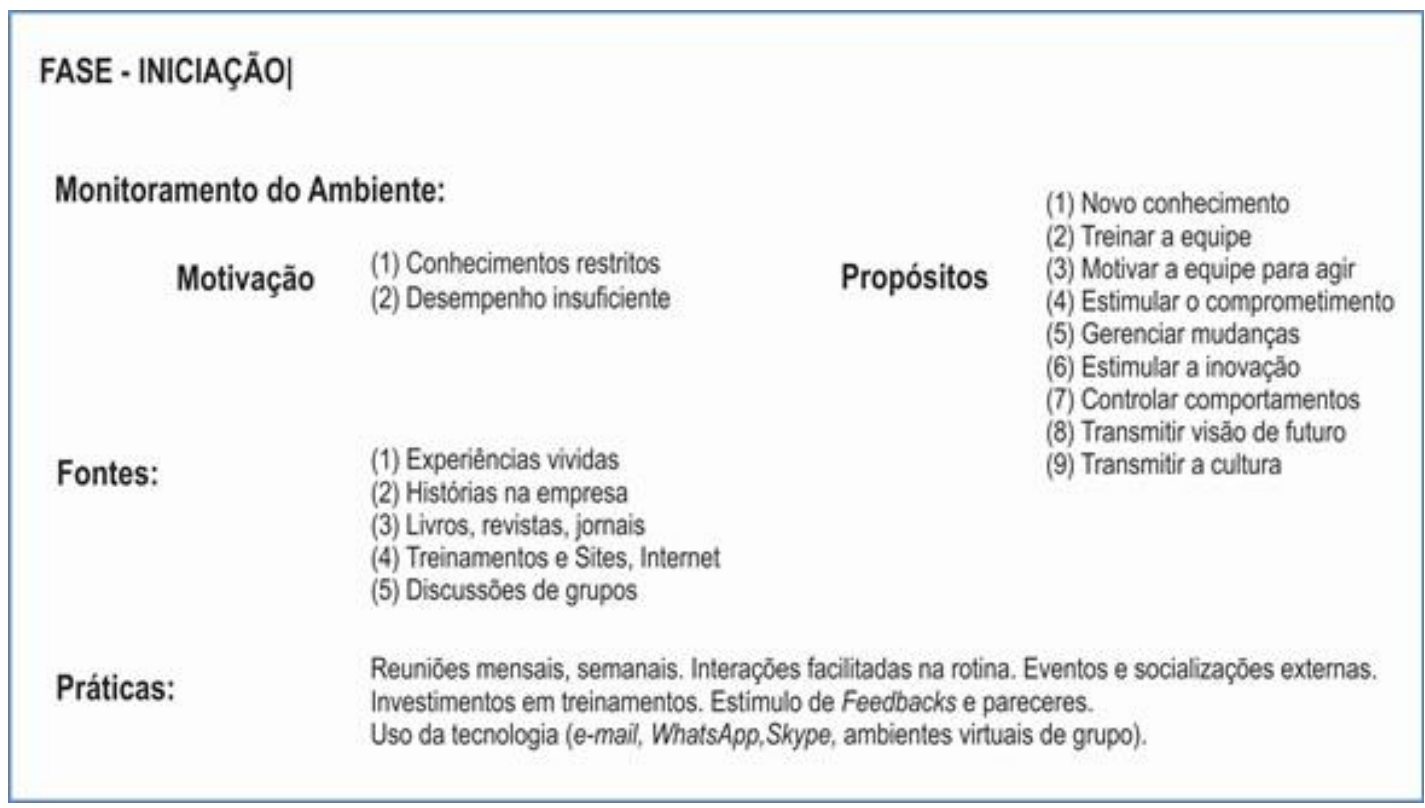

Fonte: Dados da pesquisa (2014).

Em relação à forma como as MPEs identificam as oportunidades para utilizar a narrativa para compartilhar conhecimentos, observou-se uma predominância de estímulos para compartilhar aqueles conhecimentos que estão ou são restritos a alguma(s) pessoa(s) dentro da organização. Portanto, supõe-se que a gestão trabalha estruturada e preventivamente para que 0 conhecimento esteja disponível (acessível) quando for requerido, sem que prejudique o negócio com desempenhos insuficientes da equipe ou erros repetidos.

No tocante aos propósitos da narrativa e às fontes utilizadas, observouse que, dependendo do grau de incorporação do conhecimento, proporcionalmente, as construções narrativas tendem a ser baseadas nas experiências individuais e situações vivenciadas na própria empresa, devido à dificuldade de codificar o conhecimento. Em geral, a principal intenção dos gestores pesquisados é compartilhar um novo conhecimento ou uma novidade, seja para o indivíduo ou para a empresa. Dessa forma, os propósitos em destaque no Quadro 2 convergem para a essência do compartilhamento de conhecimento, que é na visão dos pesquisados a de melhorar práticas, fazer mais e melhor, para atingir melhores níveis de qualidade do serviço e 
permanência da empresa no mercado. Porém, sair do nível macro e trabalhar os propósitos bem definidos e orientados para situações específicas pode auxiliar os gestores na descoberta de novas competências, saindo da gestão baseada no controle que naturalmente reprime a criatividade e a inovação para uma gestão baseada no conhecimento e clareza dos resultados.

O estímulo à criatividade e à inovação não foi destacado como principais propósitos, visto que apareceram no relato de apenas alguns gestores que atuam mais em nível estratégico e que demonstraram preocupação em estimular o compartilhamento de conhecimento para a criação de algo novo.

As narrativas, em alguns casos, se evidenciaram compostas por relatos de situações vivenciadas e informações obtidas em treinamentos. Essa combinação, segundo os gestores pesquisados, faz com que a mensagem fique mais receptiva por seu público. Mesmo com alto grau de conhecimento técnico, entende-se que a prática de referenciar conhecimentos obtidos em treinamentos favorece a disseminação devido à sua procedência. Assim, advindos de uma didática, com exemplos e cercados de conceitos importantes, os conhecimentos adquiridos em treinamentos obtêm essa facilidade para a construção da narrativa e replicação entre diferentes grupos de receptores.

Algumas MPEs pesquisadas apresentaram-se mais estruturadas em relação ao compartilhamento de conhecimento, possuindo canais claramente definidos e incorporados na rotina da organização, por meio das práticas de treinamentos e reuniões. Os investimentos em treinamentos fazem parte da composição orçamentária dessas empresas, devido à necessidade que os gestores vislumbram sobre o conhecimento e seu valor para o desenvolvimento dos negócios.

Como prática, também identificaram-se alguns padrões com abordagens e propósitos específicos, tais como "conversas de manutenção" e "solicitação de feedbacks". O primeiro padrão abrange mensagens de alinhamento de objetivos e de motivação para o comprometimento e são aplicadas de tempos em tempos para manter o nível de empenho da equipe. Assim, verificou-se que 
há necessidade da narrativa ser composta com a combinação de propósitos, dentro de uma abordagem para gerar resultados à empresa.

De acordo com a relevância dessa etapa para o compartilhamento de conhecimento, considera-se que as condições formais capazes de sustentar a criação de conhecimento, no entanto, estabelecem um contexto favorável com ações simples de estímulo a conversações e feedbacks.

\subsection{Fase de Implementação da Narrativa no Compartilhamento de Conhecimento nas MPEs}

Considerando as ações voltadas à promoção da integração entre emissor e destinatários do conhecimento e a forma como são suportadas as narrativas no compartilhamento de conhecimento nas MPEs, no Quadro 3 são apresentados os resultados obtidos com as empresas pesquisadas. Salienta-se que os números que aparecem nos elementos ordenam as respostas por frequência de repetição, ou seja, o número (1) repetiu mais vezes que o (2) e assim sucessivamente.

Quadro 3 - Resumo dos elementos do fluxo que implementam a narrativa nas MPEs

\begin{tabular}{|c|c|c|c|}
\hline \multicolumn{4}{|c|}{ FASE - IMPLEMENTAÇĀO| } \\
\hline Formas de Interação & $\begin{array}{l}\text { (1) Durante o expediente } \\
\text { (2) Diacrónica } \\
\text { (3) Individual/ Grupo } \\
\text { (4) Planejada e estruturadas } \\
\text { (5) Em local exclusivo } \\
\text { (6) Sincrônica (treinamentos) } \\
\text { (7) Grupo }\end{array}$ & Mecanismos de Suporte & $\begin{array}{l}\text { (1) Recorre à exemplos, fatos, } \\
\text { histórias, metáforas } \\
\text { (2) Mostra como fazer } \\
\text { trabalhando junto } \\
\text { (2) Recorre à regras e } \\
\text { procedimentos escritos, livros } \\
\text { (3) Cria novas regrase } \\
\text { procedimentos escritos }\end{array}$ \\
\hline Check-list Repositórios & $\begin{array}{l}\text { Soffware, Repositório con } \\
\text { Business Inteligence, Ch. }\end{array}$ & $\begin{array}{l}\text { m niveis de acesso. Check-list ef } \\
\text { amento via ambiente virtual, e-ma }\end{array}$ & $\begin{array}{l}\text { las de atendimento (temporário). } \\
\text { Skype, WhatsApp. }\end{array}$ \\
\hline
\end{tabular}

Fonte: Dados da pesquisa (2014).

No Quadro 3, apresentam-se os elementos do fluxo de informação, que caracterizam a implementação da narrativa no compartilhamento de 
conhecimento nas empresas pesquisadas, de acordo com os elementos: formas de interação e mecanismos de suporte.

O tempo dedicado às interações e trocas de conhecimento varia de gestor para gestor. Aqueles que apresentam menor tempo de interação com a equipe suportam a baixa interação pessoal com o uso de canais impessoais e tecnologias da informação. Entretanto, no contexto desses gestores, existem momentos formais (reuniões) para compartilhamento face a face em grupo, que acontecem com alto nível de interações (diacrônica) e intensificam e favorecem as demais trocas impessoais.

Quanto à forma como as interações acontecem, identificou-se que em contextos específicos de rotina (processo de negócio) de curto prazo e com maior fluxo de clientes, pode ocorrer inibição do desenvolvimento de algumas construções narrativas e tornar mecânico esse momento tão substancial à evolução do negócio. A busca por agilidade faz com que as pessoas queiram a informação pronta e a ansiedade pelo resultado pode dificultar ou distorcer 0 propósito do compartilhamento. Porém, algumas empresas, de modo mais planejado conseguem ir mais além com suas narrativas e, fora desse contexto no qual o tempo é fator limitante, os fluxos iniciam-se estimulados a agregarem valor e a desenvolverem novas ideias.

Prioritariamente, dentre as empresas pesquisadas, os conhecimentos narrados pelos gestores são suportados com exemplos e metáforas e também demonstrações de como fazer, trabalhando junto aos receptores. Dependendo do grau de incorporação do conhecimento, quando mais tácito e em nível experiencial ele se configura para o emissor, a narrativa pode ser sustentada com o uso das técnicas de modelagem e/ou simulação, mostrando como fazer e/ou simulando uma realidade para potencializar 0 processo de compartilhamento de conhecimentos.

Algumas empresas pesquisadas dispõem de mais conhecimentos codificados, de processos bem definidos e softwares de gestão da informação, e ao mesmo tempo em que suportam suas narrativas com exemplos e metáforas, apoiam-se em procedimentos e normas formais já estabelecidos, e 
à medida que se desenvolvem, determinam novas regras para sustentar a mudança.

Esses elementos de suporte auxiliam no compartilhamento de conhecimento das MPEs, na medida em que oferecem força à narrativa, porque em alguns casos nos quais o conhecimento não está claramente codificado, pode ser mais custoso expressar em palavras ou somente com exemplos uma nova ideia.

Contar uma história (exemplos, fatos) durante o fluxo de trabalho é muito mais fácil para compartilhar conhecimento que se envolver em um processo de orientação, análise de caso, modelagem ou observação, que levam mais tempo (SOLE; WILSON, 2002). No entanto, existem momentos que contar histórias não é propício. Em casos emergenciais, geralmente, o nível de compartilhamento fica baixo, pois o foco é a solução (a resposta) e não o processo. O receptor espera do emissor (gestor) mais do que uma história ou exemplo para agir rapidamente. No entanto, o significado pode ser resgatado posteriormente, numa reflexão sobre a situação, levantando-se os elementos importantes para o sucesso ou insucesso, ou seja, transformar o caso numa história sobre o que se deve fazer e/ou o que não se deve fazer. Essa é uma das etapas da criação de sentido levantadas por Weick, Sutcliffe e Obstfeld (2005) para criar conhecimento e impulsionar as pessoas a agirem. Dentre os gestores pesquisados, identificou-se o uso dessa técnica por alguns deles, os quais conduzem reuniões e discussões abertas para avaliar os serviços entregues e estimulam, também, a autoavaliação do desempenho individual.

Para algumas empresas pesquisadas, o canal pessoal para comunicação é o determinado, principalmente naquelas em que os gestores participam mais da rotina e que, mesmo não interagindo diretamente com a equipe, eles podem ser observados. De acordo com Nonaka e Takeuchi (1997), a socialização permite a observação e a troca de conhecimentos tácitos entre as pessoas. No entanto, o baixo nível de formalidade, nesse caso, pode resultar na perda de conhecimento. Sem valorização e registro para ser incorporado, o conhecimento pode ser perdido ou descartado. Empresas que 
estruturam a informação em momentos formais e utilizam a tecnologia para registrar o conhecimento, estão investindo na construção de uma nova base cognitiva para o desenvolvimento de ações futuras.

Em relação ao uso das tecnologias da informação, como suporte para promover as interações, percebeu-se que incorporá-las na rotina é uma realidade dos novos negócios. Foi possível notar maior frequência de uso, nas empresas com até cinco anos de existência no mercado. Com base em Linde (2001), a inteligência, nesse caso, está no uso de canais dominados pela empresa e por sua equipe, exigindo dos receptores o menor esforço possível para ter acesso às informações e ao conhecimento.

Portanto, em relação à relevância da implementação da narrativa para o compartilhamento de conhecimento, verificou-se que os gestores conseguem perceber o potencial para a melhoria do seu negócio, disseminando os conhecimentos com a aplicação prática imediata que atendem as necessidades do receptor e da organização.

\subsection{Fase de Apoio e Incorporação da Narrativa no Compartilhamento de Conhecimento nas MPEs}

A fase de apoio à incorporação do novo conhecimento pressupõe a necessidade e a existência de oportunidades para esclarecer e retificar conhecimentos repassados que ainda mereçam atenção, para evitar que passem a ser usados de forma ineficiente, inadequada ou evitar que fiquem no esquecimento e não se repliquem as práticas, a fim de que sejam incorporados à rotina. Em várias pesquisas sobre compartilhamento de conhecimento em MPEs, os autores travam uma discussão sobre práticas para reduzir os elementos tácitos do conhecimento e indicam a adoção de rotinas e práticas repetidas, para facilitar a incorporação (THORPE et al., 2005).

Com base nisso, considera-se que a percepção de assimilação acontece nas MPEs participantes na fase de implementação da narrativa durante a interação, seja por meio de perguntas explícitas sobre o entendimento ou por meio da observação das expressões faciais do receptor. Ou seja, a fase de 
apoio se inicia numa condição pessoal entre emissor e receptor para que a prática de fato se estabeleça. Nesse sentido, essa fase retroalimenta a fase de iniciação do compartilhamento de conhecimento com o monitoramento do ambiente, identificando a necessidade de reiniciar o fluxo com 0 desenvolvimento de novas narrativas, caso o resultado não seja o esperado ou oferecer estímulos para iniciar um novo fluxo, com a definição de novos propósitos.

Em relação às práticas de gestão das MPEs para monitorar e garantir a incorporação do conhecimento, identificou-se que algumas empresas conseguem acompanhar os resultados por meio de indicadores de desempenho, enquanto outras observam mudanças individuais e coletivas de comportamento, estimulam feedbacks e acompanham a qualidade do trabalho entregue, baseadas em ferramentas e procedimentos formais de controle ligados à produção do serviço.

Os conhecimentos relacionados à produção dos serviços em andamento têm o suporte de software, checklist, e-mail, ferramentas utilizadas por todas as MPEs pesquisadas. Ficou evidente a preocupação em estruturar os fluxos que envolvem 0 atendimento aos clientes, tais como o fluxo de informações relacionadas à produção do serviço. Entretanto, em relação às experiências que surgem durante a prática da produção dos serviços pergunta-se: Como as MPEs estimulam a socialização e o auxílio à criação de significados? Formalmente em reuniões de grupo para avaliar os trabalhos realizados e estabelecer novos padrões de ação, ou por meio de indicadores de desempenho, e de análises comparativas entre os resultados obtidos e os esperados, se determina a necessidade ou não novas intervenções. A criação de significados também ocorre informalmente na rotina das MPEs pesquisadas, como método para reforçar a aprendizagem, na qual, por meio de conversas individuais ou em grupo, tenta-se, apresentando o estudo do caso, compreender melhor a situação, para identificar possíveis causas de um problema ou simplesmente fortalecer procedimentos existentes. Assim sendo, considera-se que existem ferramentas e são utilizadas pelas MPEs, para 
auxiliar no desenvolvimento do negócio e a diferença nos resultados está na formalidade como a ferramenta é empregada para valorizar fluxos de conhecimentos importantes e sustentar a melhoria de práticas, de forma continuada.

Em relação à relevância dessa etapa, relacionada ao esforço para remover obstáculos ao uso do conhecimento compartilhado, constatou-se nas empresas pesquisadas, que muitos conhecimentos não estão disponíveis com livre acesso para oferecer autonomia ao receptor quando esse necessita e, com isso, precisam de mais esforços para localizar as fontes (geralmente os gestores-proprietários). Além dessas barreiras, a pesquisa evidenciou as seguintes: falta de tempo para conversar e interagir; falta de pontos de vista em comum; treinamento insuficiente; resistência do receptor em aceitar o novo conhecimento; dificuldade do receptor em compreender o novo conhecimento; falta de tempo para pensar em um discurso.

\subsection{Considerações sobre o Estudo Realizado}

Neste estudo, considerando o compartilhamento de conhecimento advindo do gestor-proprietário como um aspecto essencial para a criação de valor e competitividade das MPEs, agregou-se aos estudos sobre fluxo de informação a perspectiva da narrativa para o compartilhamento de conhecimento.

Para Misoczky e Imasato (2005), narrativa se refere a uma sequência de eventos, estados mentais, acontecimentos com o envolvimento de seres humanos como personagens, transmitido oralmente nas organizações, num fluxo vertical de cima para baixo (do gestor-proprietário para sua equipe). Portanto, a narrativa é a mensagem do fluxo, e contém informações articuladas para alcançar os objetivos pretendidos, que precisam estar bem claros de modo a ter evidências sobre os resultados alcançados. Nesse sentido, foram encontradas dificuldades na percepção desses propósitos na estrutura organizacional das MPEs pesquisadas. Desse modo, o que pode acontecer são níveis diferentes de conhecimento transmitidos com a mensagem, 
dependendo de como são construídas (fontes de argumentos e destaque da trama), da clareza do propósito para ambos, emissor e receptor, da maneira como acontece a interação ou como estão fazendo uso de outros recursos para dar suporte a mensagem (conhecimentos codificados, observação ou modelagem, simulação e storytelling).

Observaram-se vários aspectos importantes nessa pesquisa: empresas compartilhando informações informais e contribuindo para uma comunicação mais humanizada, que combina experiências com embasamento advindo de conhecimento codificado (regras e processos implementados); empresas que intensificam seu fluxo de informação com ações formais de compartilhamento visando desenvolver as competências estratégicas necessárias para a empresa operar com excelência; outras que se configuram de forma mais participativa, moldada a nova realidade das redes sociais $e$ ao compartilhamento de conhecimento, dando mais vozes aos membros da equipe que, em grande parte, é composta por profissionais especializados e detentores de competências distintas.

Em relação à interação com a equipe, destacam-se empresas com maior representatividade de interações na rotina dentro do ambiente organizacional e também maior informalidade. Observou-se que essa situação pode ser problemática para o compartilhamento de conhecimento, à medida que tais interações se estabeleçam cada vez mais naturalmente na rotina, para suprir a baixa capacidade cognitiva da equipe, ou disfarçar problemas de recrutamento e seleção.

Em algumas das empresas pesquisadas, as interações são formalizadas com a intenção principal de desenvolvimento dos serviços a serem entregues, ou seja, de acordo com a demanda de serviços. Desse modo, nota-se que o conhecimento é produzido para contextos específicos e apenas se integram à base de conhecimento da organização, quando são codificados como itens de checklist e processos. Com isso, é possível que se garanta uma evolução, à medida que é disseminado como procedimento padrão. 
Findadas as análises, com a apresentação de aspectos críticos percebidos em relação às práticas de algumas empresas pesquisadas, as principais considerações são: (i) simplificação da atividade e pouca visão em relação à agregação de valor, por meio do conhecimento para poder desenvolver o negócio. Entende-se que é um aspecto que, de certa forma, bloqueia o compartilhamento de conhecimento a partir da falta de visão em relação a novas opções de atuação para buscar conhecimentos; (ii) excesso de formalidade e comunicação sincrônica, no sentido de valorizar apenas o que é formalizado. De acordo com Davenport e Prusak (1998, p. 108) "a transferência espontânea e não estruturada do conhecimento é vital para o sucesso de uma empresa." Para essa prática, o equilíbrio pode ser alcançado estimulando a espontaneidade da equipe e; (iii) desequilíbrio no uso de informações de convívio e de atividade nas narrativas, destacando-se que as informações de atividades a serem transmitidas de forma objetiva, podem tocar menos no emocional das pessoas e na capacidade delas agirem com entusiasmo. Portanto, é essencial combinar o uso das duas informações (convívio e atividade) a fim de oferecer um significado ampliado acerca do "o que fazer?", com a adição de respostas para "por que fazer?" e "como fazer?", contextualizar com informações de convívio de tal forma que o indivíduo consiga se ambientar na perspectiva do novo conhecimento ou ideia.

\section{CONSIDERAÇÕES FINAIS}

As considerações finais são conduzidas para responder ao problema de pesquisa: como acontece a narrativa no fluxo de informação para compartilhar conhecimento e de que maneira ela sustenta a melhoria de processos e práticas de serviços MPEs.

Pressupondo que o conhecimento resultante dos fluxos de informações sustenta o desenvolvimento de melhores práticas e processos de serviços, incrementando os resultados e a competitividade das organizações, a partir da ação racionalizada ou dirigida pela gestão, consideram-se as narrativas como 
mensagens estruturadas que suportam os conhecimentos e os fluxos de informação como canal de suporte para disseminá-las.

O estudo da narrativa foi conduzido nas MPEs dos Núcleos Setoriais da ACIF, tendo como método de observação e análise o modelo teórico desenvolvido com base no levantamento referencial, acerca de fluxos de informação no contexto do compartilhamento de conhecimento em organizações (TONET; PAZ, 2006).

A construção da narrativa manifesta-se, em geral, de forma intuitiva, confirmando as evidências de Brusamolin e Moresi (2008). Diante disso, apresentam-se as seguintes considerações sobre o estudo realizado:

- o estímulo para dar início à narrativa e promover a interação, acontece para disseminar conhecimentos que estão restritos a algumas pessoas na organização;

- os propósitos das narrativas, de modo geral, visam o compartilhamento de um novo conhecimento, o treinamento da equipe, bem como a motivação para agir;

- para construir a argumentação e a trama da narrativa, as fontes utilizadas são, principalmente, experienciais particulares e de terceiros, com a combinação de conhecimentos advindos do ambiente externo e interno;

- as interações de implementação da narrativa acontecem, formalmente, nos fluxos relacionados à produção. No entanto, os fluxos de gestão, geralmente não são formalizados. As interações acontecem tanto entre os gestores e cada profissional individualmente como em grupo, não sendo possível identificar preferências. Na realidade, são utilizadas de acordo com as oportunidades dos momentos e dependendo dos temas abordados;

- os mecanismos de suporte à narrativa mais utilizados, são os exemplos, as histórias e os fatos que aconteceram na empresa. As metáforas foram citadas por dois entrevistados por as considerarem como a melhor forma de transmitir conhecimentos. Porém, o uso de 
metáforas e analogias da mesma forma que possibilita às pessoas a compreensão de algo de modo intuitivo, por meio de símbolos (NONAKA, 2000), exige maior criatividade e desenvoltura por parte do emissor, impactando na amplificação de seu uso;

- as práticas de controle aplicadas pelos gestores para impulsionar a nova prática de serviço mais utilizadas, relacionam-se aos fluxos de atividades dos serviços a serem entregues e se constituem em estímulos a feedbacks, conversas e ferramentas e procedimentos formais (fichas de serviços, checklists) e, em casos de gestão mais estruturada, acompanhamento do negócio por meio de indicadores de desempenho e;

- no tocante às dificuldades no processo de compartilhamento de conhecimento por meio da implementação narrativa, os gestores revelaram que a maior dificuldade é promover a mudança e instigar a percepção de valor do receptor pelo novo conhecimento. De maneira essencial, os gestores apontaram a adoção de novas práticas como uma questão real que impede o compartilhamento de conhecimento (DAVENPORT; PRUSAK, 1998).

Apesar disso, foi possível perceber que o problema pode ser resultado tanto da abordagem utilizada pela própria gestão na construção da narrativa para atingir o receptor e os resultados, como da estrutura do fluxo de informação, no sentido de oferecer o apoio necessário à incorporação e prática do novo conhecimento.

\section{REFERÊNCIAS}

ALE EBRAHIM, N.; AHMED, S.; TAHA, Z. Virtual R\&D teams and SMEs growth: a comparative study between Iranian and Malaysian SMEs. African Journal of Business Management, Nigeria, v. 4, n. 11, p. 2368-2379, 2010.

BARDIN, L. Análise de conteúdo. Lisboa: Edições 70, 2009. 
BARRETO A. A. A informação em seus momentos de passagem. Revista de Ciência da Informação, Rio de Janeiro, v. 2, n. 4, ago. 2001. Disponível em: <http://ridi.ibict.br/bitstream/123456789/171/1/BarretoDataGramaZero2001.pdf> . Acesso em: 01 jun. 2014.

. A questão da informação. São Paulo em Perspectiva, São Paulo, v. 8, n. 4, p. 3-8, 1994.

. O rumor do conhecimento. São Paulo em Perspectiva, São Paulo, v. 12, n. 4 , p. 69-77, 1999.

. O tempo e o espaço da ciência da informação. Transinformação, Campinas, v. 14, n. 1, p. 17-24, 2002.

BOISOT, M. Knowledge assets: securing competitive advantage in the information economy. Oxford: Oxford University Press, 1998.

. Moving to the edge of chaos: bureaucracy, it and the challenge of complexity. Journal of Information Technology, v. 21, n. 4, p. 239-248, dez. 2006.

BOISOT, M. H.; LI, Y. Organizational versus markets knowledge: from concrete embodiment to abstract representation. Journal of Bioeconomics, v. 8, n. 3, p. 219-251, 2006.

BRUSAMOLIN, V. Emprego de narrativas de histórias na gestão de projetos de tecnologia da informação. 2006. 143 f. Dissertação (Mestrado em Gestão do Conhecimento e da Tecnologia da Informação) - Universidade Católica de Brasília, Brasília, 2006.

A inserção do discurso narrativo no ciclo informacional e seu impacto na aprendizagem organizacional. 2011. $312 \mathrm{f}$. Tese (Doutorado em Ciência da Informação) - Universidade de Brasília, Brasília, 2011.

BRUSAMOLIN, V.; MORESI, E. Narrativas de histórias: um estudo preliminar na gestão de projetos de tecnologia da informação. Ciência da Informação, Brasília, v. 37, n. 1, p. 37-52, 2008.

$\mathrm{CHOO}, \mathrm{C}$. W. A organização do conhecimento: como as organizações usam a informação para criar significado, construir conhecimento e tomar decisões. 2. ed. São Paulo: Senac, 2006.

CURTY, R. G. O fluxo da informação tecnológica no projeto de produtos em indústrias de alimentos. 2005. 249 f. Dissertação (Mestrado em Ciência da Informação) - Universidade Federal de Santa Catarina, Florianópolis, 2005. 
DAVENPORT, T. H.; PRUSAK, L. Conhecimento empresarial: como as organizações gerenciam o seu capital intelectual. Rio de Janeiro: Campus, 1998.

DENNING, S. O poder das narrativas nas organizações: o guia para líderes sobre o uso da técnica de narrativas. Rio de Janeiro: Elsevier Brasil: Petrobras, 2006.

DURST, S.; EDVARDSSON, I. R. Knowledge management in SMEs: a literature review. Journal of Knowledge Management, v. 16, n. 6, p. 879-903, 2012.

GARGIULO, T. L. Stories at work: using stories to improve communication and build relationships. USA: Praeger Publishers, 2006.

GASSMANN, O.; KEUPP, M. M. The competitive advantage of early and rapidly internationalising SMEs in the biotechnology industry: a knowledge-based view. Journal of World Business, v. 42, n. 3, p. 350-366, 2007.

GIL, A. C. Métodos e técnicas de pesquisa social. São Paulo: Atlas, 1999.

GONÇALVES, C. O.; RAMOS, D. S. F.; SANTOS, M. S. Gestão do conhecimento e comunicação organizacional: estudo da aplicação de um modelo de comunicação organizacional para disseminação do conhecimento. 2009. 83 f. Trabalho de Conclusão de Curso (Especialização em Gestão do Conhecimento e Inteligência Empresarial) - Universidade Federal do Rio de Janeiro, 2009.

INOMATA, D. O. O fluxo da informação tecnológica: uma análise no processo de desenvolvimento de produtos biotecnológicos. 2012. $282 \mathrm{f}$. Dissertação (Mestrado em Ciência da Informação) - Universidade Federal de Santa Catarina, Florianópolis, 2012.

LESCA, H.; ALMEIDA, F. C. Administração estratégica da informação. Revista de Administração da FEA/USP, São Paulo, v. 29, n. 3, p. 66-75, jul./set. 1994.

LINDE, C. Narrative and social tacit knowledge. Journal of Knowledge Management, [S.I.], v. 5, n. 2, p. 160-171, 2001.

MARCONI, M. A.; LAKATOS, E. M. Técnicas de pesquisa: planejamento e execução de pesquisas, amostragens e técnicas de pesquisa, elaboração, análise e interpretação de dados. 6. ed. São Paulo: Atlas, 2007.

MISOCZKY, M. C; IMASATO, T. Narrativas e histórias nos estudos organizacionais: um diálogo sobre referências e práticas. Revista Economia \& Gestão, Minas Gerais, v. 5, n. 11, p. 77-96, 2005. 
NONAKA, I. A empresa criadora de conhecimento. In: Harvard Business Review. Gestão do Conhecimento. 5. ed. Rio de Janeiro: Campus, 2000, p. $27-80$.

NONAKA, I.; TAKEUCHI, H. Criação de conhecimento na empresa. Rio de Janeiro: Campus, 1997.

PASSOS, K. G. F. O fluxo de informação no processo de desenvolvimento de jogos eletrônicos. 2012. 223 f. Dissertação (Mestrado em Ciência da Informação) - Universidade Federal de Santa Catarina, Florianópolis, 2012.

SANTOS, T. C. S. Narrativa no fluxo de informação durante o compartilhamento de conhecimento em MPEs: um estudo multicaso nos núcleos setoriais e câmaras da ACIF. 2014. 202 f. Dissertação (Mestrado em Ciência da Informação) - Universidade Federal de Santa Catarina, Florianópolis, 2014.

SOLE, D.; WILSON, D. G. Storytelling in organizations: the power and traps of using stories to share knowledge in organizations. LILA, Harvard, Graduate School of Education, p. 1-12, 2002.

STRAUSS, A. L.; CORBIN, J. M. Pesquisa qualitativa: técnicas e procedimentos para o desenvolvimento de teoria fundamentada. 2. ed. Porto Alegre: Artmed, 2008.

THORPE, R. et al. Using knowledge within small and medium-sized firms: A systematic review of the evidence. International Journal of Management Reviews, v. 7, n. 4, p. 257-281, 2005.

TONET, H. C.; PAZ, M. G. T. Um modelo para o compartilhamento de conhecimento no trabalho. RAC: Revista de Administração Contemporânea, Curitiba, v. 10, n. 2, p. 75-94, abr./jun. 2006.

TRIVIÑOS, A. N. S. Introdução à pesquisa em ciências sociais: a pesquisa qualitativa em educação. São Paulo: Atlas, 1987.

VALENTIM, M. L. (Org.). Gestão, mediação e uso da informação. São Paulo: Cultura Acadêmica, 2010.

WEICK, K. E.; SUTCLIFFE, K. M.; OBSTFELD, D. Organizing and the process of sensemaking. Organization Science, [S.I.], v. 16, n. 4, p. 409-421, 2005.

YIN, R. K. Estudo de caso: planejamento e métodos. Porto Alegre: Bookman, 2005. 


\title{
NARRATIVE IN THE INFORMATION FLOW DURING THE KNOWLEDGE SHARING IN MICRO AND SMALL COMPANIES: A MULTI-CASE STUDY
}

\begin{abstract}
Introduction: While the structure of micro and small companies tend to promote the creation of new knowledge, it is believed that most of those companies do not have a systematized process that allows to share all this knowledge for creating value. Purpose: To analyze the narrative in information flow during knowledge sharing processes and how it supports the improvement of processes and service in micro and small companies. Methodology: This research has a qualitative approach, it is exploratory and descriptive. This research uses multi-case study as a technical procedure, using the universe of companies member of the Commercial and Industrial Association of Florianópolis. Results: The survey evidences show that the narratives support the development of better service practices, increasing company results and competitiveness, from the streamlined action directed by management. The flow of information process itself is the channel of such practices, which depend of the knowledge of the owner-managers and are presented on an individual level. Conclusions: The study contributes with a new perspective for analyzing the information flow, by inserting the narrative to support the improvement of processes and organizational practices in micro and small companies.
\end{abstract}

Descriptors: Information flow. Knowledge sharing. Micro and small companies. Narrative.

\section{NARRATIVA EN EL FLUJO DE INFORMACIÓN PARA EL INTERCAMBIO DE CONOCIMIENTO EN MICRO Y PEQUEÑAS EMPRESAS: UM ESTUDIO MULTICASO}

\begin{abstract}
RESUMEN
Introducion: Al mismo tiempo que la creación de nuevos conocimientos es promovida por la estructura de las micro y pequeñas empresas, se cree que buena parte de esas empresas no tienen un proceso sistematizado que permite compartir todo ese conocimiento, generando valor para el negocio. Meta: Observar la narrativa en el flujo de información durante el intercambio de conocimiento y la forma en que ella apoya la mejora de los procesos y prácticas de servicio en micro y pequeñas empresas. Metodología: Se trata de una investigación aplicada, con enfoque cualitativo, exploratorio y descriptivo. El estudio utilizó un estudio multicaso como procedimiento técnico para su aplicación, y el universo fue constituido por las empresas participantes de la Asociación Comercial e Industrial de Florianópolis. Resultados: Las evidencias del estudio muestran que las narrativas apoyan el desarrollo de mejores prácticas de servicio, el aumento de los resultados y competitividad en las empresas, por medio de la acción racional y dirigida por la dirección. Tales prácticas son canalizadas a través del flujo de información del propio proceso, dependen del conocimiento de los gerentes-propietarios y se presentan en un nivel individual. Conclusiones: El estudio hace un aporte una nueva perspectiva en el análisis de flujo de información con la
\end{abstract}

Inf. Inf., Londrina, v. 23, n. 2, p. 395 - 426, maio/ago. 2018.

http://www.uel.br/revistas/informacao 
inserción de la narrativa para apoyar la mejora de los procesos y prácticas de la organización de micro y pequeñas empresas.

Descriptores: Flujo de información. Intercambio de conocimientos. Micro y pequeñas empresas. Narrativa.

Recebido: 10.03. 2017

Aceito: 27.02 .2018

Inf. Inf., Londrina, v. 23, n. 2, p. 395 - 426, maio/ago. 2018

http://www.uel.br/revistas/informacao 